Only by resolving more structures will we be able to get a deeper insight into this new and interesting class of compound. When more structural information becomes available this may prove useful for the better understanding of the electronic structure of alloys, some of which have atomic patterns similar to those found in these gold clusters.

\section{References}

1 F. Cariati and L. Naldini, Inorg. Chim. Acta, 1971, 5, 172

2 M. McPartlin, R. Mason and L. Malatesta, f. Chem. Soc., Chem. Commun., 1969, 334

3 V. G. Albano, P. L. Bellon and M. Manassero, F. Chem Soc., Chem. Commun., 1970, 1210; P. L. Bellon, M. Manassero and M. Sansoni, $\mathcal{F}$. Chem. Soc, Dalton Trans., 1972, 1481
4 F. Cariati and L. Naldini, F. Chem. Soc., Dalton Trans., 1972,2286

5 P. L. Bellon, F. Cariati, M. Manassero, L. Naldini and M. Sansoni, F. Chem., Soc., Chem. Commun., 1971, 1423

6 P. L. Bellon, M. Manassero, L. Naldini and M. Sansoni, F. Chem. Soc., Chem. Commun., 1972, 1035

7 P. L. Bellon, M. Manassero and M. Sansoni, f. Chem. Soc., Dalton Trans., 1973, 2423; S. A. Bezman, M. R. Churchill, J. A. Osborn and J. Wornmald, F. Am. Chem. Soc., 1971, 93, 2063

8 L. Malatesta, L. Naldini, G. Simonetta and F. Cariati, f. Chem. Soc., Chem. Commun., 1965, 212; L. Naldini, F. Cariati, G. Simonetta and L. Malatesta, f. Chem. Soc. Chem. Commun., 1966, 647; L. Malatesta, L. Naldini, G. Simonetta and F. Cariati, Coord. Chem. Rev., 1966, 1, 255; F. Cariati, L. Naldini, G. Simonetta and L. Malatesta, Inorg. Chim. Acta, 1967, 1, 24; F. Cariati, L. Naldini, G. Simonetta and L. Malatesta, Inorg. Chim. Acta $1967,1,316$

9 R. Gregori, Thesis, University of Milan, 1973

\title{
Diffusion Barriers for Gold Plated Copper
}

\section{THE INFLUENCE OF ATOMIC RADIUS}

In certain types of circuits the gold plated copper contact elements can operate at moderately high temperatures. In these conditions copper can diffuse through the gold electrodeposit, with the result that any copper reaching the surface will oxidise, thereby increasing the contact resistance and causing further heating, and so increasing the rate of diffusion of copper to the surface. A vicious spiral can be thus created-and complete failure can result.

Nickel is, of course, commonly used as an undercoat for this reason but a research project sponsored by the American Electroplaters' Society to study the usefulness of a range of barrier layers to prevent or minimise this phenomenon has now been the subject of a first report by the two investigators, J. C. Turn of Battelle and Dr E. L. Owen of Kennecott Copper (Plating, 1974, 61, (11), 1015-1018).

Samples of pure copper that had been gold plated without a barrier layer were examined, together with a series of specimens having either an electrodeposited or an electroless deposited metallic barrier between the copper and the electrodeposited gold. The barrier metals were nickel, chromium, platinum, palladium, and rhodium, while electroless deposits of hypophosphite nickel and borane nickel were also employed. There were deposited to thicknesses of $0.25,0.5,1.0$ and $2.0 \mu \mathrm{m}$.

The specimens were diffusion heat treated at $400^{\circ} \mathrm{C}$ and $550^{\circ} \mathrm{C}$ in partial vacuum, while those without a barrier layer were also given a $750^{\circ} \mathrm{C}$ treatment. They were then protected and mounted for microscopic examination to detect any porosity or other defects.

The major part of this investigation involved the use of an electron probe microanalyser. For each specimen a profile of concentration against distance from the interface was determined, and the initial data were adjusted for fluorescence, the effects of atomic number, absorption background, and the finite diameter of the electron beam. Some irregularities were observed in these concentration-distance profiles, and a rather arbitrary factor-"copper penetration"-was therefore established as an alternative indication of the extent of diffusion of the copper into the gold electrodeposit.
This was defined as the distance on the corrected copper concentration profile from the original interface to a point corresponding with a concentration of 7.5 weight per cent of copper.

Copper penetration values determined for specimens with barrier layers of platinum, palladium and rhodium at all thicknesses tested showed no significant decreases from the values obtained for specimens without barrier layers, indicating that these metals are ineffective in retarding the penetration of copper.

The pure nickel barriers with a thickness of $1 \mu \mathrm{m}$ effectively reduced the values of copper penetration as compared with the no-barrier values, while a nickel thickness of $2 \mu \mathrm{m}$ did not generally reduce the copper penetration values below those obtained with the $1 \mu \mathrm{m}$ specimens. This finding does not, of course, agree with the generally accepted idea that increased barrier thickness should increase effectiveness.

Chromium barrier layers in all thicknesses were found to give good results, but chromium has, of course, the associated complication of needing an outgassing treatment to prevent hydrogen blistering, and a special activation step to ensure an adherent gold deposit.

Both the electroless nickel deposits were effective in decreasing copper penetration, the presence of phosphorus in the barrier layer apparently being significantly more effective; an increase in phosphorus content decreased the copper penetration, presumably due to the high volume percentage of nickel phosphide.

Perhaps the most interesting correlation to emerge from these investigations is that between the atomic radius of the barrier layer metal atoms and the degree of copper penetration. The poorer barriers-platinum, palladium and rhodium-all have atomic radii larger than that of copper, whereas the effective barriers, nickel and chromium, have a smaller radius than copper. From this relationship the authors suggest that cobalt, with atomic radius $1.252 \AA$ compared with copper at $1.276 \AA$, should be examined for its effectiveness as a means of retarding diffusion into gold electrodeposits. L. B. $\mathrm{H}$. 